\title{
Liver Yin deficiency tonifying herbal extract induces apoptosis and cell senescence in Bel-7402 human hepatocarcinoma cells
}

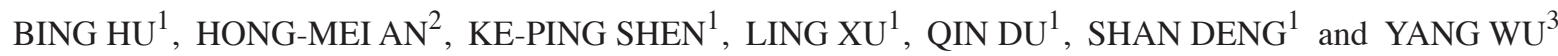 \\ ${ }^{1}$ Department of Oncology and Institute of Traditional Chinese Medicine in Oncology; ${ }^{2}$ Department of Science \\ and Technology, Longhua Hospital, Shanghai University of Traditional Chinese Medicine, Shanghai; \\ ${ }^{3}$ State Key Laboratory of Biotherapy and Cancer Center, West China Hospital, \\ West China Medical School, Sichuan University, Sichuan, P.R. China
}

Received August 23, 2011; Accepted October 3, 2011

DOI: $10.3892 / \mathrm{etm} .2011 .364$

\begin{abstract}
Liver cancer ranks as the fifth most prevalent malignancy of all cancers worldwide. According to the principles of traditional Chinese medicine, liver Yin deficiency is a common clinical syndrome of liver cancer, and tonifying liver Yin is a common treatment method for liver cancer. However, no hepatocarcinoma-specific liver Yin tonifying formula has yet been established. In the present study, we established a liver cancer-specific combination of herbs, which we term liver Yin tonifying formula (LYTF). We found that LYTF inhibits the proliferation of Bel-7402 cells in a dose- and time-dependent manner. LYTF induces apoptosis in Bel-7402 cells, which is accompanied by activation of caspases-8,-9 and -3. Pan-caspase blocking completely abrogates LYTF-induced apoptosis and partially abrogates LYTF-induced proliferation inhibition. LYTF also induces cell senescence, as indicated by a large and flattened morphology, senescence-activated $\beta$-galactosidasepositive staining and G0/G1 cell cycle arrest, accompanied by the up-regulation of p16 and p21 and the down-regulation of retinoblastoma protein phosphorylation. These findings suggest that LYTF is effective in inhibiting the growth and survival of hepatocarcinoma cells through the induction of apoptosis and cell senescence. Our study also provides insight into traditional Chinese medicine methods used for the treatment of liver cancer.
\end{abstract}

\section{Introduction}

Liver cancer remains the fifth most common malignancy worldwide, and its incidence is on the rise due to hepatitis virus infection $(1,2)$. The incidence of liver cancer is particularly high in China and Southeast Asian countries. Current treatments

Correspondence to: Dr Bing Hu, Department of Oncology, Longhua Hospital, Shanghai University of Traditional Chinese Medicine, 725 South Wanping Road, Shanghai 200032, P.R. China E-mail: beearhu@hotmail.com

Key words: hepatocarcinoma, Chinese herbal formula, apoptosis, cell senescence for liver cancer mainly include early surgical treatment, intervention, liver transplantation and targeted therapy $(2,3)$. Since liver cancer originates in an occult fashion and progresses rapidly, most patients are at the late stage at diagnosis and are no longer good candidates for surgical removal $(3,4)$. In addition, the clinical benefits of intervention or targeted therapy are limited in most patients $(5,6)$. Therefore, the development of new paradigms for liver cancer treatment is crucial.

In China, traditional Chinese medicine has been widely used in all aspects of liver cancer, including surgery, interventional and targeted therapy, even as a single treatment for advanced liver cancer, and has been confirmed to effectively control cancer progression, improve quality of life and prolong survival times, to some extent, in liver cancer patients (7-10). Liver Yin deficiency is one of the common syndromes included in or accompanying liver cancer $(11,12)$. Liver Yin tonifying herbs have been used for the treatment of liver cancer with liver Yin deficiency and are crucial elements of traditional Chinese medicine prescriptions $(13,14)$. However, the clinical application of liver Yin tonifying herbs is empirical to some extent, and there is a lack of an efficient liver Yin tonifying herbal formula for liver cancer, limiting the improvement of its efficacy.

Based on the principles of traditional Chinese medicine and progress in the pharmacological characterization of anticancer herbs, we developed a liver Yin tonifying herbal formula (LYTF) for liver cancer. Our LYTF consists of glossy privet fruit, Carapax trionycis (processed with vinegar) and Polygonum cuspidatum. Glossy privet fruit and Carapax trionycis are classic liver Yin tonifying Chinese herbs that are frequently used in the treatment of liver cancer and have demonstrated anticancer effects to some extent (15-17). Oleanolic acid, the main component of glossy privet fruit, has recently been reported to induce the apoptosis of hepatocarcinoma cells (18). Polygonum cuspidatum has anti-inflammatory, anti-viral, anti-tumor and anti-angiogenic effects, and is commonly employed in treatments for viral hepatitis and liver cancer $(10,19)$. Resveratrol, the major component from Polygonum cuspidatum, exerts desirable anticancer effects by inducing apoptosis and cell senescence in numerous types of cancer cells (20-22). In the present study, we observed that LYTF inhibited proliferation, enhanced caspase 
activity and induced apoptosis in Bel-7402 hepatocarcinoma cells. In addition, LYTF induced cell senescence in Bel-7402 cells, accompanied by the up-regulation of p16 and p21 expression and the down-regulation of retinoblastoma $(\mathrm{Rb})$ protein phosphorylation.

\section{Materials and methods}

Chemicals and reagents. RPMI-1640 medium and fetal bovine serum (FBS) were obtained from Hyclone (Logan, UT, USA). The Cell Counting Kit-8 (CCK8) was purchased from Dojindo (Kumamoto, Japan). The FITC Annexin V Apoptosis Detection kit was obtained from BD Biosciences Pharmingen (San Diego, CA, USA). The Colorimetric CaspACE ${ }^{\mathrm{TM}}$ Assay System was the product of Promega (Madison, WI, USA). Z-VAD-FMK, Caspase-8 and Caspase-9 Colorimetric Assay kits were procured from R\&D Systems (Minneapolis, MN, USA). Antibodies against p16, p21, Rb, phospho-Rb, poly(ADPribose)polymerase (PARP) and $\alpha$-tubulin were the product of Cell Signaling Technology (Danvers, MA, USA). The Hoechst Staining kit was obtained from Beyotime (Jiangsu, China). The Senescence $\beta$-Gal Staining kit was purchased from Cell Signaling Technology.

Herbal preparation. LYTF was prepared as a lyophilized dry powder of hot water extracts as described previously (23-25). Authentic herb materials were from the Longhua Hospital herb store. The herbs used were glossy privet fruit (24 g), Carapax trionycis (processed with vinegar) $(60 \mathrm{~g})$ and Polygonum cuspidatum $(30 \mathrm{~g})$. All herbs were soaked for $1 \mathrm{~h}$ and decocted twice with an 8 -fold volume of distilled water for $2 \mathrm{~h}$. The decoction was filtered and centrifuged twice at 12,000 rpm for $30 \mathrm{~min}$ to remove insoluble ingredients. The supernatants were mixed with an equal volume of ethanol, maintained at $4^{\circ} \mathrm{C}$ overnight and centrifuged at $12,000 \mathrm{rpm}$ for $30 \mathrm{~min}$ to remove insoluble ingredients. The resultant supernatants were lyophilized, weighed, dissolved in RPMI-1640 medium and adjusted to a concentration of $400 \mathrm{mg} / \mathrm{ml}$, and were sequentially passed through 0.45 and $0.22 \mu \mathrm{m}$ sterilization filters.

Cell culture. The Bel-7402 human hepatocarcinoma cell line and HL-7702 human hepatocyte cells were obtained from the Cell Bank of Type Culture Collection of the Chinese Academy of Sciences. Bel-7402 and HL-7702 cells were grown in RPMI-1640 medium with 10\% FBS and 1\% Pen-Strep, and maintained at $37^{\circ} \mathrm{C}$ in a humidified incubator with a $5 \% \mathrm{CO}_{2}$ atmosphere.

Cell growth inhibition assay. Cells in the logarithmic growth phase were seeded into 96 -well plates $\left(4 \times 10^{3}\right.$ cells/well) and allowed to attach for $24 \mathrm{~h}$ prior to treatment. The cells were exposed to various doses of LYTF for $72 \mathrm{~h}$, and cell viability was evaluated every $24 \mathrm{~h}$ using the CCK- 8 colorimetric assay, according to the manufacturer's instructions. The cell survival rate was calculated as follows: cell survival rate $(\%)=$ experimental optical density (OD) value/control OD value x $100 \%$.

Detection of apoptosis. Bel-7402 cells were treated with various doses of LYTF for $72 \mathrm{~h}$, stained with $5 \mu \mathrm{g} / \mathrm{ml}$ Hoechst 33258 in the dark for $5 \mathrm{~min}$ and assessed under fluorescence micros-
A

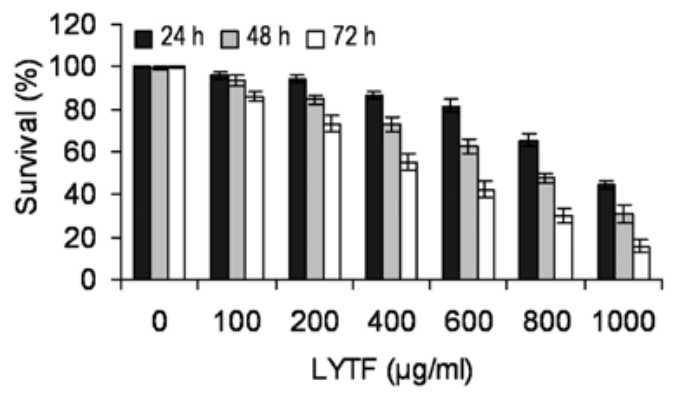

B

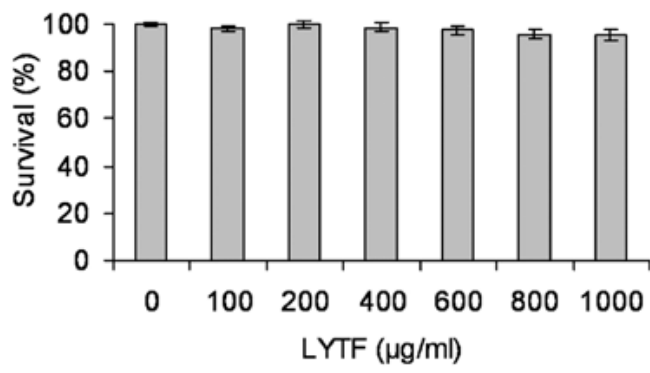

Figure 1. Effects of LYTF on the proliferation of Bel-7402 and HL-7702 cells. (A) Human hepatocarcinoma Bel-7402 cells and (B) human normal hepatocyte HL-7702 cells were treated with various concentrations of liver Yin tonifying formula (LYTF) for $72 \mathrm{~h}$. Cell viability was evaluated every $24 \mathrm{~h}$ by CCK- 8 assay. Data shown are representative of three independent experiments. CCK-8, Cell Counting Kit-8.

copy. For flow cytometric analysis, LYTF-treated Bel-7402 cells were collected, stained with Annexin V-FITC and PI as recommended by the manufacturer, and detected in a FACScalibour flow cytometer (Becton-Dickinson).

Caspase activity assay. Following treatment with varying concentrations of LYTF, caspase-3, -8 and -9 activities were measured by the cleavage of the specific chromogenic substrate according to the manufacturer's instructions. For caspase inhibition, cells pre-treated with Z-VAD-FMK (50 $\mu \mathrm{mol} / 1,2 \mathrm{~h})$ were incubated with LYTF for a further $72 \mathrm{~h}$.

Senescence-activated $\beta$-galactosidase staining (SA- $\beta$-gal). Bel-7402 cells $\left(3 \times 10^{4}\right)$ were plated in $35-\mathrm{mm}$ diameter plates and treated with $200 \mu \mathrm{g} / \mathrm{ml}$ of LYTF for 5 days. SA- $\beta$-gal staining was performed according to the manufacturer's instructions (Cell Signaling Technology).

Western blot analysis. Western blot analysis was performed as described previously (24). Briefly, collected cells were lysed and subjected to $8-12 \%$ sodium dodecyl sulfate polyacrylamide gel electrophoresis (SDS-PAGE) and transferred onto a nitrocellulose membrane (Amersham Biosciences, Buckinghamshire, UK). The transferred membrane was blocked with $5 \%$ nonfat milk, washed and probed with the indicated antibodies. Blots were then washed and incubated with IRDye 700- and IRDye 800-conjugated secondary antibodies (Rockland Immunochemicals, Gilbertsville, PA, USA), and visualized in Odyssey Infrared Imaging System (LI-COR Biosciences, Lincoln, NE, USA).

Statistical analysis. Results are expressed as the means \pm standard deviation of at least two independent experiments, 
A
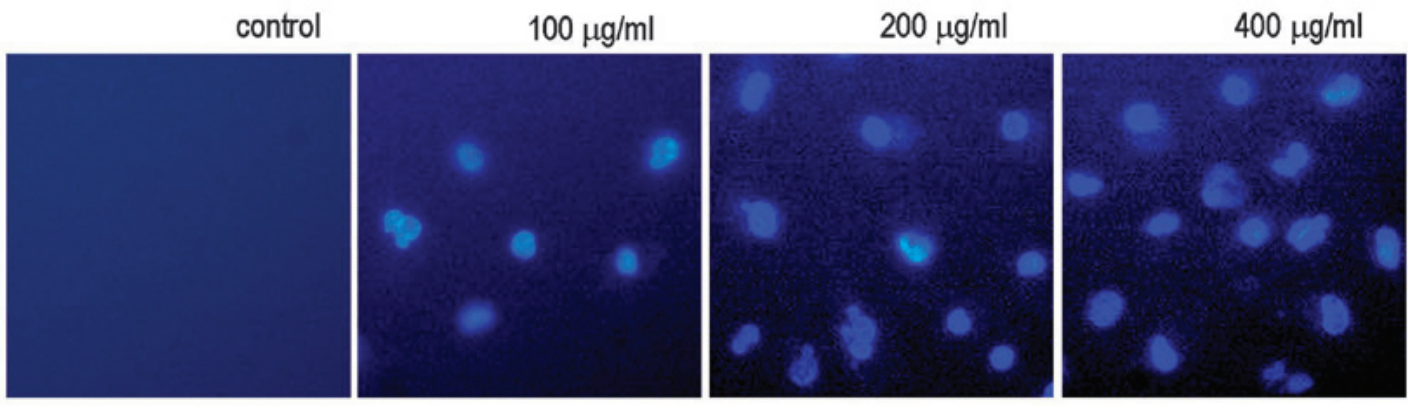

$\mathbf{B}$
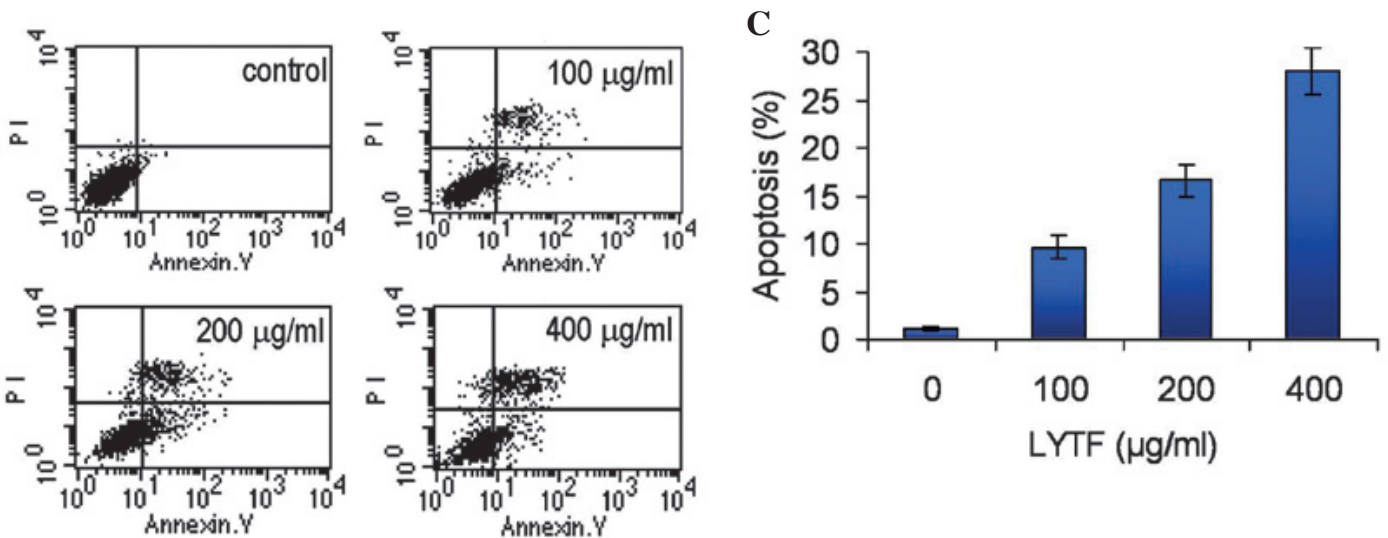

Figure 2. LYTF-induced apoptosis in Bel-7402 cells. (A) Bel-7402 cells were treated with indicated doses of LYTF for 72 h, stained with Hoechst 33258 and observed under a fluorescence microscope (magnification, x400). Apoptotic cells were further confirmed by (B) Annexin V/PI staining and (C) flow cytometric analysis, and expressed as the means \pm SD. LYTF, liver Yin tonifying formula; SD, standard deviation.

each conducted in triplicate. Differences between the control and LYTF-treated cells were analysed by one-way ANOVA. Differences were considered significant at $\mathrm{P}<0.05$.

\section{Results}

LYTF inhibits the proliferation of Bel-7402 cells. To determine the effects of LYTF on the growth of Bel-7402 cells, the CCK-8 assay was performed. At a final concentration of 100-1,000 $\mu \mathrm{g} / \mathrm{ml}, \mathrm{LYTF}$ inhibited the proliferation of Bel-7402 cells in a dose- and time-dependent manner (Fig. 1A) $(\mathrm{P}<0.05)$. By contrast, LYTF had no significant effect on the proliferation of human normal hepatocyte HL-7702 cells at these concentrations (Fig. 1B).

LYTF induces apoptosis of Bel-7402 cells. Following $72 \mathrm{~h}$ of incubation with 100-400 $\mu \mathrm{g} / \mathrm{ml}$ of LYTF, Bel-7402 cells were stained with Hoechst 33258. We observed dense blue fluorescent particles within the nucleus or cytoplasm in addition to significant nuclear morphological changes, indicating the occurrence of apoptotic processes (Fig. 2A). Flow cytometric analysis further confirmed that incubation with $100-400 \mu \mathrm{g} / \mathrm{ml}$ of LYTF for $72 \mathrm{~h}$ induced considerable apoptosis of Bel-7402 cells, compared to the control group (Fig. $2 \mathrm{~B}$ and $\mathrm{C})(\mathrm{P}<0.01)$.

Role of caspases in LYTF-induced anticancer effects. To determine whether caspases attributed to the LYTF-induced apoptosis in Bel-7402 cells, the activities of caspase-3, -8 and -9 were measured by the cleavage of the specific substrate. Caspase activity assays revealed that LYTF was capable of activating caspases-3, -8 and -9 in Bel-7402 cells to varying degrees in a dose-dependent manner (Fig. 3A-C) $(\mathrm{P}<0.01)$. In addition, PARP, one of the earliest substrates of caspase-3 during apoptosis (26), was also cleaved following LYTF treatment (Fig. 3D). Furthermore, the LYTF-induced apoptosis of Bel-7402 cells was completely abrogated by the pan-caspase inhibitor, Z-VAD-FMK (Fig. 4A) $(\mathrm{P}<0.01)$, suggesting that the LYTF-induced apoptosis was associated with caspase signaling cascades. To our surprise, the inhibitory effects of LYTF on the proliferation of Bel-7402 cells were partially abrogated by the Z-VAD-FMK inhibitor (Fig. 4B) $(\mathrm{P}<0.01)$, suggesting that there may be another mechanism contributing to the LYTF-induced anticancer effects.

LYTF induces cell senescence in Bel-7402 cells. With lowdose LYTF treatment, partial Bel-7402 cells exhibited a large and flattened morphology, reminiscent of cell senescence (Fig. 5A-b). Therefore, SA- $\beta$-gal staining was performed. As shown in Fig. 5B-a and $-b$, LYTF treatment resulted in SA- $\beta$ gal-positive staining, compared to the controls. By contrast, neither morphology nor SA- $\beta$-gal activity was affected by LYTF treatment in normal HL-7702 hepatocytes (Fig. 5B-c and $-\mathrm{d})$. In addition, flow cytometric analysis revealed that the cell cycle of LYTF-treated Bel-7402 cells was arrested in the G0/G1 phase (Fig. 6) $(\mathrm{P}<0.01)$. These observations suggest that LYTF may induce senescence in Bel-7402 cells.

Effects of LYTF on the expression of senescence-associated genes. The effects of LYTF on the expression of senescence-associated genes in Bel-7402 cells were detected by Western blot analysis. As shown in Fig. 7, treatment with LYTF caused an up-regulation in the expression of p21 and 
A

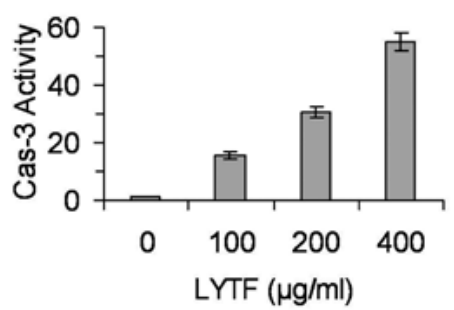

C

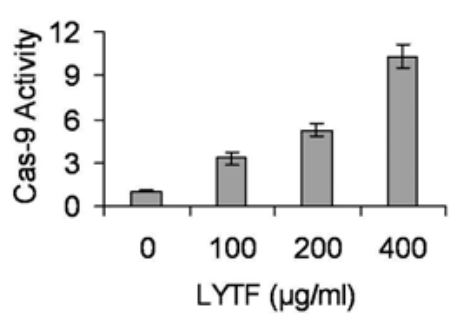

B

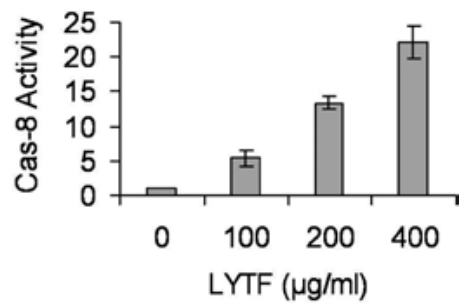

D

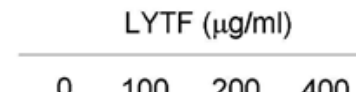

c-PARP

$0 \quad 100 \quad 200 \quad 400$

$\alpha$-Tubulin

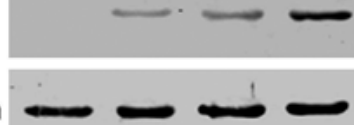

Figure 3. LYTF activated caspases in Bel-7402 cells. Bel-7402 cells were treated with various doses of LYTF for $72 \mathrm{~h}$; (A) caspase-3, (B) caspase-8 and (C) caspase-9 activity were detected as described in Materials and methods. Caspase activities were expressed as fold activation over the control. (D) Cleaved PARP (c-PARP) was detected by Western blot analysis with specific antibody. $\alpha$-tubulin was used as the loading control. Cas, caspase; PARP, poly(ADP-ribose) polymerase; LYTF, liver Yin tonifying formula.

A

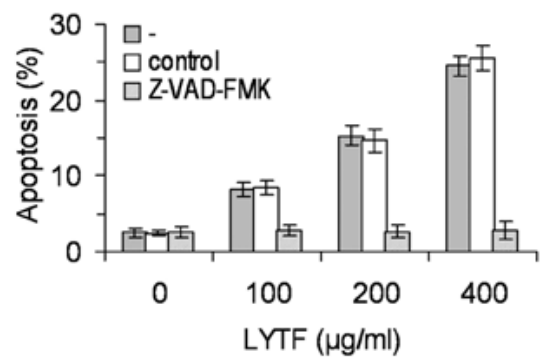

B

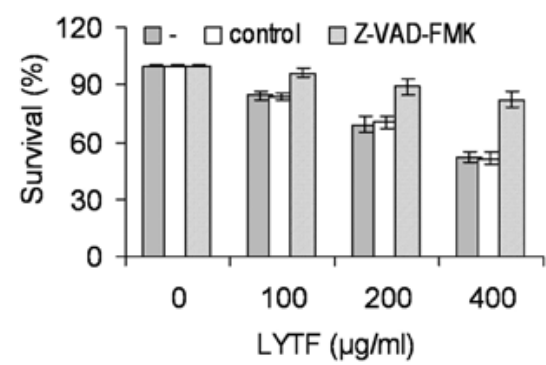

Figure 4. Role of caspases in LYTF-induced anticancer effects in Bel-7402 cells. Following pre-treatement with Z-VAD-FMK (50 $\mu$ mol/l) for $2 \mathrm{~h}$, Bel-7402 cells were exposed to $100-400 \mu \mathrm{g} / \mathrm{ml} \mathrm{LYTF}$ for $72 \mathrm{~h}$, and subjected to apoptosis detection by (A) flow cytometry and (B) CCK-8 assay. Data presented are from three separate experiments. LYTF, liver Yin tonifying formula; CCK-8, Cell Counting Kit-8.

A
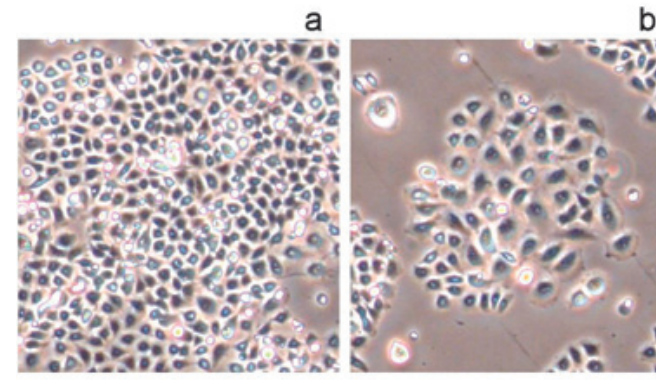

B
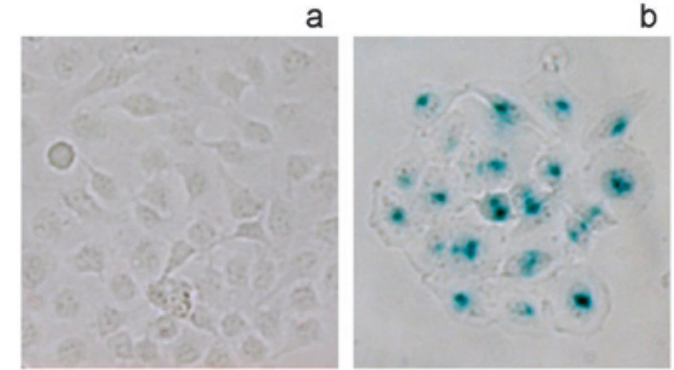

b

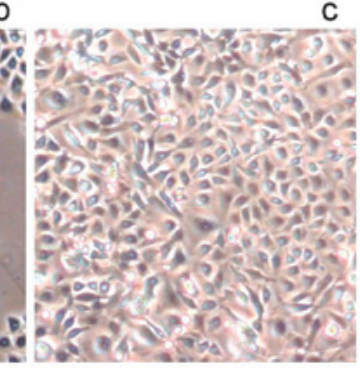

C

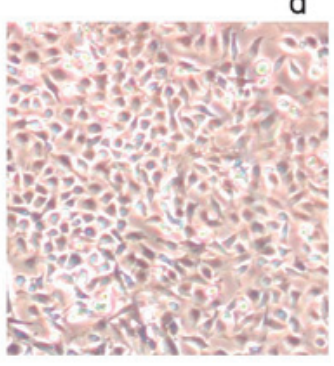

b

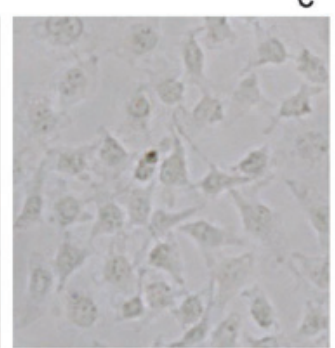

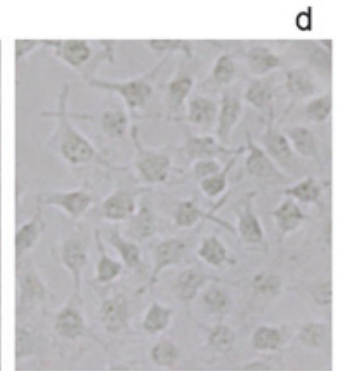

Figure 5. LYTF activated SA- $\beta$-gal in Bel-7402 cells. (A) Bel-7402 cells (a and b) and HL-7702 cells (c and d) were treated with $200 \mu \mathrm{g} / \mathrm{ml} \mathrm{LYTF}$ for 5 days. Cell morphology observed under a microscope (magnification, $\mathrm{x} 200$ ), and (B) subjected to SA- $\beta$-gal staining and observed under a microscope (magnification, $\mathrm{x} 400)$. LYTF, liver Yin tonifying formula; SA- $\beta$-gal, senescence-activated $\beta$-galactosidase. 
A

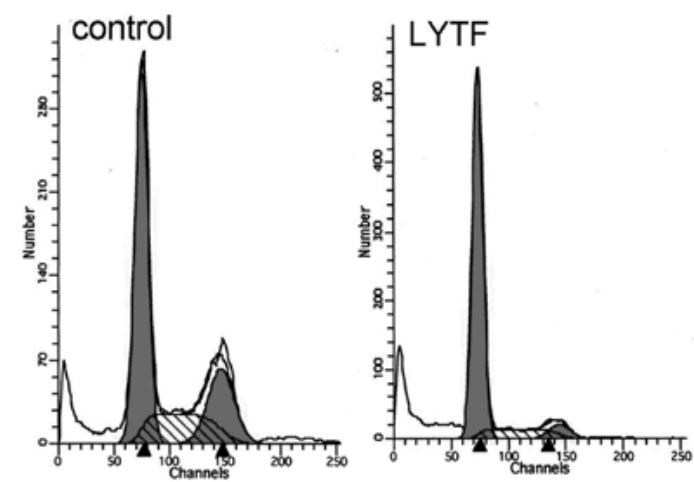

B

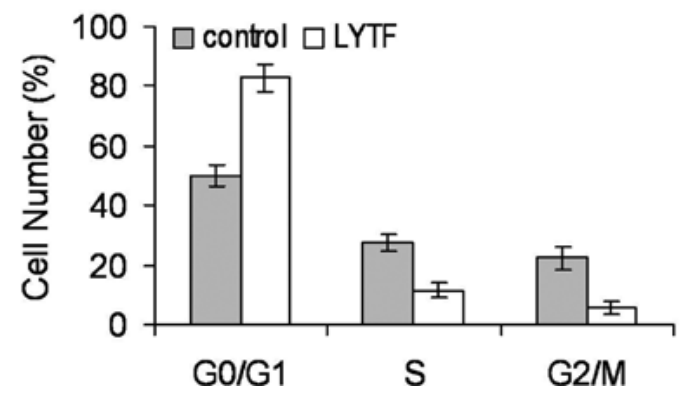

Figure 6. LYTF induced cell cycle arrest in Bel-7402 cells. (A) Cell cycle distribution of LYTF $(200 \mu \mathrm{g} / \mathrm{ml})$-treated Bel-7402 cells was analysed by flow cytometry and expressed as the means \pm SD (B). LYTF, liver Yin tonifying formula; SD, standard deviation.

p16. Expression levels of $\mathrm{Rb}$ did not change, but $\mathrm{Rb}$ phosphorylation was inhibited by LYTF treatment. These results suggest that the LYTF-induced cell senescence of Bel-7402 cells is related to elevated $\mathrm{p} 21$ and $\mathrm{p} 16$ expression and inhibition of $\mathrm{Rb}$ phosphorylation.

\section{Discussion}

Current cancer pharmacotherapy strategies, such as chemotherapy and targeted therapy, act on cancer cells mainly through apoptosis, cell senescence, autophagy and other mechanisms to achieve therapeutic effects $(27,28)$. Apoptosis is an evolutionarily conserved cell suicide process elicited by physiological, pharmacological and pathological conditions. The initiation and execution of apoptosis depends on the activation of the extrinsic and/or intrinsic death pathways $(28,29)$. Extrinsic or death receptor pathways are associated with death receptors, such as FAS, the TRAIL receptor (TRAIL-R) and TNF receptor (TNF-R). On binding to the corresponding ligands, such as FasL, TRAIL or TNF $\alpha$, death receptors oligomerize and their death domains undergo conformational changes to facilitate the interaction with the adaptor protein, Fas-associated death domain (FADD), resulting in the recruitment of caspase- 8 to form the death-inducing signaling complex. Activated caspase- 8 then activates caspase-3, triggering apoptosis. Conversely, intrinsic or mitochondrial pathways involve signals to the mitochondria that lead to the release of cytochrome $\mathrm{c}$ and Apaf-1, forming an apoptosome that activates the initiating protease caspase- 9 , which, in turn, activates caspase-3, causing the cell to undergo apoptosis. The activation of caspases- 8 and -9 are the hallmark events of extrinsic and intrinsic apoptotic

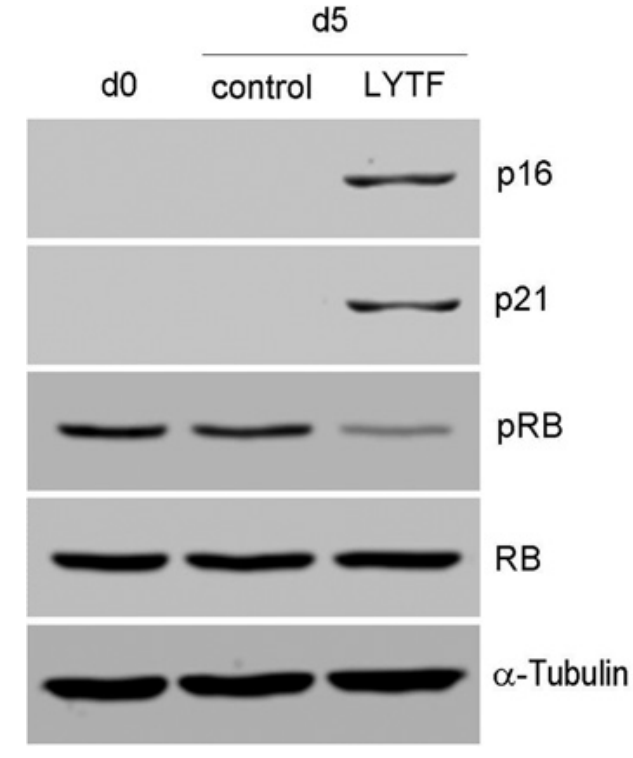

Figure 7. Effects of LYTF on the expression of cell senescence regulatory genes. Bel-7402 cells were collected following LYTF $(200 \mu \mathrm{g} / \mathrm{ml})$ treatment and subjected to Western blot analysis using antibodies against p16, p21, Rb and $\mathrm{pRb}$. $\alpha$-tubulin was used as the loading control. LYTF, liver Yin tonifying formula; $\mathrm{Rb}$, retinoblastoma; $\mathrm{pRb}$, phosphorylated retinoblastoma.

pathways, respectively. In the present study, following LYTF treatment, Bel-7402 cells exhibited apoptotic morphology. The apoptotic cells were detected by flow cytometry. Furthermore, LYTF activates caspases-3, -8 and -9 , and the LYTF-induced apoptosis may be blocked by a caspase inhibitor. These results indicate that the LYTF-induced apoptosis of Bel-7402 cells is closely related to caspase activation.

Cell senescence is a state of stable, irreversible cell cycle arrest provoked by a variety of stimuli. Senescent cells maintain some metabolic activity, but can no longer proliferate, even if stimulated with mitogens. Cell senescence is usually characterized by a large and flattened morphology, an increase in intracellular granules and elevated SA- $\beta$-gal activity (30). Similar to apoptosis, cell senescence plays a crucial role in suppressing tumorigenesis and may contribute to the outcome of cancer therapy (29-32). It has been shown that chemotherapeutic agents, such as cisplatin, doxorubicin, SN-38 and camptothecin, inhibit the growth of tumors via cell senescence (32-35). Cell senescence as a tumor suppression mechanism has increasingly attracted attention in recent times (36). We observed that LYTF treatment caused Bel-7402 cells to assume a large and flat morphology, test positive for SA- $\beta$-gal staining and become arrested in the G0/G1 phase of the cell cycle, suggesting that LYTF treatment induces senescence in these cells.

The occurrence of cell senescence is closely related to the activation of the CDKN1a (p21WAF-1/Cip1)/pRB/E2F or CDKN2a (p16INK4A)/pRB/E2F signaling pathway $(37,38)$. p21, a crucial cell cycle regulator, inhibits a variety of cyclin/ CDK complexes and induces the hypophosphorylation or dephosphorylation of protein $\mathrm{Rb}(\mathrm{pRb})$. Hypophosphorylated $\mathrm{pRb}$ binds to $\mathrm{E} 2 \mathrm{~F}$ and prevents it from activating target genes that are essential in the cell cycle, usually leading to cell cycle arrest. p21 plays a crucial role in cancer cell senescence, dependent or independent of p53 $(31,35,39)$. The CDK4 and 
CDK6 inhibitor, p16, also participates in the regulation of $\mathrm{Rb}$ phosphorylation, induces cell cycle arrest and may contribute to the induction of cell senescence $(25,34,40,41)$. An increase in p16 and p21 expression and the inhibition of Rb phosphorylation was observed in Bel-7402 cells following LYTF treatment, suggesting that the LYTF-induced cell senescence of Bel-7402 is associated with these processes. Moreover, the inhibition of Rb phosphorylation by LYTF may be due to the collaboration of p21 and p16.

In conclusion, our study demonstrates that LYTF inhibits proliferation and activates caspase cascades to induce apoptosis in Bel-7402 hepatocarcinoma cells. Furthermore, LYTF also induces senescence in Bel-7402 cells, which may correlate with the increased expression of p16 and p21, and the inhibition of $\mathrm{Rb}$ phosphorylation. The present study provides new insights into traditional Chinese medicine approaches to liver cancer treatment that are worth pursuing.

\section{Acknowledgements}

This study was partially supported by the Key Basic Research Program from the Science and Technology Commission of Shanghai Municipality (09JC1413600), the Program for Long-Yi Scholars and Research Team in State Clinical Research Center of TCM (LYTD-04), the Key Discipline of State Administration of Traditional Chinese Medicine (Traditional Chinese Medicine in Oncology) and the Shanghai Shen Kang Platform Grant (SHDC12007206). The authors would also like to thank the Shanghai Key Laboratory of Tissue Engineering for providing technical assistance.

\section{References}

1. Jemal A, Bray F, Center MM, Ferlay J, Ward E and Forman D: Global cancer statistics. CA Cancer J Clin 61: 69-90, 2011.

2. Hagymási K and Tulassay Z: Epidemiology risk factors and molecular pathogenesis of primary liver cancer. Orv Hetil 149: $541-548,2008$.

3. Rampone B, Schiavone B and Confuorto G: Current management of hepatocellular cancer. Curr Oncol Rep 12: 186-192, 2010.

4. Lord R, Suddle A and Ross PJ: Emerging strategies in the treatment of advanced hepatocellular carcinoma: the role of targeted therapies. Int J Clin Pract 65: 182-188, 2011.

5. Oliveri RS, Wetterslev J and Gluud C: Transarterial (chemo) embolisation for unresectable hepatocellular carcinoma. Cochrane Database Syst Rev 16: CD004787, 2011.

6. Wysocki PJ: Targeted therapy of hepatocellular cancer. Expert Opin Investig Drugs 19: 265-274, 2010.

7. Yu Y, Lang Q, Chen Z, Li B, Yu C, Zhu D, Zhai X and Ling C: The efficacy for unresectable hepatocellular carcinoma may be improved by transcatheter arterial chemoembolization in combination with a traditional Chinese herbal medicine formula: a retrospective study. Cancer 115: 5132-5138, 2009.

8. Meng MB, Cui YL, Guan YS, Ying Z, Zheng MH, Yuan CK and Zhang RM: Traditional Chinese medicine plus transcatheter arterial chemoembolization for unresectable hepatocellular carcinoma. J Altern Complement Med 14: 1027-1042, 2008.

9. Shu X, McCulloch M, Xiao H, Broffman M and Gao J: Chinese herbal medicine and chemotherapy in the treatment of hepatocellular carcinoma: a meta-analysis of randomized controlled trials. Integr Cancer Ther 4: 219-229, 2005.

10. Du Q, Hu B, Shen KP and An HM: Progress in TCM pathogenesis and treatment of liver cancer. World J Integr Tradit West Med 5: 814-817, 2010.

11. Hou FG, Ling CQ, Zhao G and He XM: Investigation of clinical distribution of basic TCM Syndrome in primary hepatic carcinoma. Shanghai J Tradit Chin Med 39: 22-23, 2005.
12. Wu YF, Wang SP, Sun JM and Wei JN: Clinical distribution and standards of TCM Syndrome of primary hepatic carcinoma. J Shanxi Coll Tradit Chin Med 8: 21-23, 2007.

13. Pan MQ, Zeng PH and Pan B: Regularity of traditional Chinese medicine in middle and advanced primary hepatic carcinoma. Chinese Arch Tradit Chin Med 21: 1641-1642, 2003.

14. Liu Q, Zhang YB, Ma CH, Yue XQ and Ling CQ: Analysis of literature on therapeutic methods and medicines of traditional Chinese medicine for primary liver cancer. J Chin Integr Med 3: 260-262, 2005.

15. Xiang M, Gu ZL, Zhou WX and Guo CY: Anti-cancer effects of extract of glossy privet fruit in vivo. Jiangsu Pharm Clin Res 10: $13-15,2002$.

16. Li L, Qiu RL, Cheng G, Shi Y, Han Y, Gao Y and Lu Y: The study on the anti-tumor effect of polysaccharides from glossy privet fruit in vitro and in vivo. Chin Pharm Bull 24: 1619-1622, 2008.

17. Du Q, Hu B and Shen KP: A Survey of anti-cancer effects of Chinese tonifying herbs in primary hepatic carcinoma. J Chin Med Mater 33: 1512-1516, 2010.

18. Yan SL, Huang CY, Wu ST and Yin MC: Oleanolic acid and ursolic acid induce apoptosis in four human liver cancer cell lines. Toxicol In Vitro 24: 842-848, 2010.

19. Yang JM, Yang BB, Zhang A, Wang JQ and Zhang B: The research and development of Polygounm cuspidatum. Acta Agric Boreali-occidentalis Sinica 13: 156-159, 2004.

20. Feng L, Zhang LF, Yan T, Jin J and Tao WY: Studies on active substance of anticancer effect in Polygonum cuspidatum. J Chin Med Mater 29: 689-691, 2006.

21. Delmas D, Solary E and Latruffe N: Resveratrol, a phy tochemical inducer of multiple cell death pathways: apoptosis, autophagy and mitotic catastrophe. Curr Med Chem 18: 1100-1121, 2011.

22. Gao Z, Xu MS, Barnett TL and Xu CW: Resveratrol induces cellular senescence with attenuated mono-ubiquitination of histone H2B in glioma cells. Biochem Biophys Res Commun 407: 271-276, 2011.

23. Hsu YL, Kuo PL, Tzeng TF, Sung SC, Yen MH, Lin LT and Lin CC: Huang-lian-jie-du-tang, a traditional Chinese medicine prescription, induces cell-cycle arrest and apoptosis in human liver cancer cells in vitro and in vivo. J Gastroenterol Hepatol 23: e290-e299, 2008.

24. Hu B, Shen KP, An HM, Wu Y and Du Q: Aqueous extract of curcuma aromatica induces apoptosis and $\mathrm{G} 2 / \mathrm{M}$ arrest in human colon carcinoma LS-174-T cells independent of p53. Cancer Biother Radiopharm 26: 97-104, 2011.

25. Hu B, An HM, Shen KP and Du Q: Senescence-inducing effects of Chinese herbal medicine Tenglong Buzhong Decoction on human colon carcinoma LS-174-T cells and the mechanism. J Chin Integr Med 8: 1048-1052, 2010.

26. Lazebnik YA, Kaufmann SH, Desnoyers S, Poirier GG and Earnshaw WC: Cleavage of poly(ADP-ribose)polymerase by a proteinase with properties like ICE. Nature 371: 346-347, 1994.

27. Brown JM and Attardi LD: The role of apoptosis in cancer development and treatment response. Nat Rev Cancer 5: 231-237, 2005.

28. Meier P and Vousden KH: Lucifer's labyrinth - ten years of path finding in cell death. Mol Cell 28: 746-754, 2007.

29. Chiantore MV, Vannucchi S, Mangino G, Percario ZA, Affabris E, Fiorucci G and Romeo G: Senescence and cell death pathways and their role in cancer therapeutic outcome. Curr Med Chem 16: 287-300, 2009.

30. Schmitt CA: Cellular senescence and cancer treatment. Biochim Biophys Acta 1775: 5-20, 2007.

31. Ewald JA, Desotelle JA, Wilding G and Jarrard DF: Therapyinduced senescence in cancer. J Natl Cancer Inst 102: 1536-1546, 2010.

32. Gewirtz DA, Holt SE and Elmore LW: Accelerated senescence: an emerging role in tumor cell response to chemotherapy and radiation. Biochem Pharmacol 76: 947-957, 2008.

33. Di X, Shiu RP, Newsham IF and Gewirtz DA: Apoptosis, autophagy, accelerated senescence and reactive oxygen in the response of human breast tumor cells to adriamycin. Biochem Pharmacol 77: 1139-1150, 2009.

34. Te Poele RH, Okorokov AL, Jardine L, Cummings J and Joel SP: DNA damage is able to induce senescence in tumor cells in vitro and in vivo. Cancer Res 62: 1876-1883, 2002.

35. Han Z, Wei W, Dunaway S, Darnowski JW, Calabresi P, Sedivy J, Hendrickson EA, Balan KV, Pantazis P and Wyche JH: Role of p21 in apoptosis and senescence of human colon cancer cells treated with camptothecin. J Biol Chem 277: 17154-17160, 2002. 
36. Nardella C, Clohessy JG, Alimonti A and Pandolfi PP: Pro-senescence therapy for cancer treatment. Nat Rev Cancer 11: 503-511, 2011

37. Roninson IB: Tumor cell senescence in cancer treatment. Cancer Res 63: 2705-2715, 2003.

38. Dimri GP: What has senescence got to do with cancer. Cancer Cell 7: 505-512, 2005.

39. Lodygin D, Menssen A and Hermeking H: Induction of the Cdk inhibitor p21 by LY83583 inhibits tumor cell proliferation in a p53-independent manner. J Clin Invest 110: 1717-1727, 2002.
40. Chang UM, Li CH, Lin LI, Huang CP, Kan LS and Lin SB: Ganoderiol F, a ganoderma triterpene, induces senescence in hepatoma HepG2 cells. Life Sci 79: 1129-1139, 2006.

41. Xing R, Li W, Cui J, Zhang J, Kang B, Wang Y, Wang Z, Liu S and $\mathrm{Lu} \mathrm{Y}$ : Gastrokine 1 induces senescence through $\mathrm{p} 16 / \mathrm{Rb}$ pathway activation in gastric cancer cells. Gut: June 14, 2011 (E-pub ahead of print). 